\title{
O FEMINISMO DE VIRGINIA WOOLF E A LITERATURA PÓS-COLONIAL
}

\author{
Márcio André Senem \\ in memoriam
}

Resumo: O Feminismo e Pós-Colonialismo são movimentos que surgiram no século $\mathrm{XX}$ no âmbito das Ciências Sociais e, nos estudos literários, procuram analogamente desconstruir o cânone literário hegemonicamente europeu e patriarcal, para então entendê-lo e modificar as estruturas performáticas dos indivíduos, possibilitando a eles uma interação ainda maior com a literatura e todas as áreas do conhecimento e expressão humana. A partir Um teto todo seu, obra da escritora inglesa Virginia Woolf (1928), este texto procura estabelecer uma relação com as expressões e conceitos utilizados por ambos os movimentos e mostrar que possuem semelhança no que querem dizer e atingir. A referida obra de Virginia Woolf, direcionada à emancipação da mulher, consiste em uma conferência em uma universidade inglesa para um público feminino, mostra que os problemas das mulheres são semelhantes ao silêncio imposto às ações dos indivíduos de países que são ex-colônias de países europeus. Por isso, estudando as teorias do Pós-Estruturalismo, pretende-se referendar a analogia pretendida para discutir e estabelecer ainda mais características dos movimentos feministas e do próprio Pós-Colonialismo. Mulheres negras africanas, por exemplo, são silenciadas pela herança do patriarcalismo e do colonialismo e encontram agora mecanismos para serem ouvidas e expressar seus conhecimentos sobre a vida e o mundo.

Palavras-chave: Feminismo; Pós-Colonialismo; Virginia Woolf.

Abstract: Feminism and Post-Colonialism are movements that emerged in the 20th century within the Social Sciences and that similarly attempt to deconstruct the hegemonically European and patriarchal literary canon in order to understand it and to modify the individuals' performatic structures, allowing them a greater interaction with literature and all the areas of human knowledge and expression. From the work A room of one's own (1928), written by the English author Virginia Woolf, we intend to make a relation of the expressions and concepts used by both movements, and to demonstrate the similarities in what they wish to say and to accomplish. Virginia Woolf's work, that was directed to the emancipation of women and written for a conference given at a British University for a female audience, shows that women's problems are similar to the silence imposed on the actions of the individuals from countries that are former colonies of European countries. Therefore, by studying the theories of post-structuralism, the intended analogy may be referred so as to discuss and to establish further more characteristics to the feminists movements and to post-colonialism itself. African black women, for example, who have been silenced by patriarchalism e by colonialism left as heritages, now find mechanisms to be heard and to express their knowledge about life and the world.

Keywords: Feminism; Post-Colonialism; Virginia Woolf. 
O Feminismo e o Pós-Colonialismo identificam-se pela causa de ruptura e desconstrução do cânone literário, hegemonicamente europeu até o fim do século XIX. Esses movimentos interagem e se relacionam um com o outro, pois possuem ambos o objetivo de proporcionar mudanças e de dar voz a quem não possui espaço na formação do mundo contemporâneo. (BONNICI, 1999, p. 198)

Mas a dicotomia dessa relação é muito anterior. De acordo com a maioria dos filósofos iluministas, a paixão e a imaginação, mas nunca o conceito, constituíam-se como qualidades das mulheres. Elas não seriam capazes de invenção, e mesmo quando tinham a possibilidade de acesso à literatura e a determinadas ciências, estariam excluídas da genialidade. Nelas, portanto, a inferioridade da razão era um fato incontestável, bastando-lhes cultivá-la na medida necessária ao cumprimento de seus deveres naturais: obedecer ao marido, ser-lhe fiel, cuidar dos filhos. As mulheres não eram tratadas como sujeito e buscava-se impedir a sua fala e a sua atividade. ${ }^{1}$

É importante repensar e historicizar o feminismo. O ponto de partida das estudiosas feministas do início do século XX foi buscar, desde os levantes da Grécia Antiga, como a poetisa Sappho ${ }^{2}$, considerar as discriminações contra as mulheres ${ }^{3}$. Concordando com a abordagem apresentada, podemos dizer que, além do fato de se auto-afirmarem como feministas, as precursoras do movimento no século $\mathrm{XX}$ encaixam-se perfeitamente nos critérios de definição construídos pelos ideais de igualdade de gênero, ainda que a definição tenha sido criada a partir de uma realidade distinta. A partilha da África no século XX e a luta pelos direitos civis das mulheres surgem quase no mesmo momento, sincronizando-se nas suas discussões.

Os termos empregados no discurso pós-colonialista passam a ser empregados no discurso feminista, pois o silêncio imposto parte da mesma fonte, a Europa dominadora que tinha se estruturado no pensamento patriarcal. Um ponto em comum, explícito neste estudo, é que a teoria pós-colonial e a teoria feminista concluem, em se tratando do valor estético dos textos literários, que foram construídos historicamente sob a égide do patriarcalismo e do eurocentrismo. Os enfoques teóricos explicitam, assim, a nãouniversalidade do cânone europeu e põem abaixo a hegemonia destas definições (BONNICI, 1999, p. 198). A teoria feminista contemporânea estabelece o princípio da diferença como a constituição do outro, da alteridade, indo contra os teóricos europeus e norte-americanos que reduzem a luta feminina ao essencialismo do ponto de vista da mulher branca anglo-saxã (ibid., p. 199).

No ensaio Um teto todo seu (1929), Virginia Woolf caracteriza-se como uma das precursoras do feminismo, negando a dicotomia metafísica entre masculino e feminino. Esse ensaio surgiu de duas palestras realizadas em 1928 para platéias femininas ${ }^{4}$. A mulher ${ }^{5}$ e sua postura na sociedade, o modo como é vista e faz literatura, não encontram uma verdade absoluta nos estudos que Virginia Woolf desenvolve para escrever seu texto. Sua reflexão serve para pensar a postura e o lugar da mulher hoje, tendo em vista os variados conceitos de Feminismo e de Pós-Colonialismo. Atualmente, a mulher pode ter suas próprias opiniões e conclusões ao se deparar com os cânones literários e com as possibilidades da liberdade, construída a partir da necessidade da igualdade entre homens e mulheres, como indica Mary Wollstonecraft em $A$ Vindication of the Rights of Woman, de 1792 (MOTTA, 2003). Isso permite que a figura feminina faça e entenda o mundo, utilizando-se da androginia do gosto para observar a literatura e sua construção. Assim, a própria mulher desconstrói os conceitos já estabelecidos e hierarquizados pelo eurocentrismo e pelo sexismo masculino. A mulher tem então a oportunidade de observar suas limitações em seu contexto e deparar seus conceitos e preconceitos com os da autora, bem como com suas idiossincrasias ${ }^{6}$.

Sem dúvida, Virginia Woolf pratica a androginia textual ${ }^{7}$ na construção de seu 
ensaio, pois se vale de todas as liberdades e licenças de um romancista. Ela constrói uma ponte entre a conferência, o ensaio e a ficção da qual se utiliza para melhor ser percebida e entendida, fazendo com que sua platéia possa entendê-la e tirar suas conclusões. A subjetividade e a fantasia a situam na tradição ensaística que não descarta ambos os conceitos. Quando se utiliza dessa androginia textual, Virginia Woolf recusa um tom decisivo em suas observações, por colocar tais problemas apresentados como não-solucionados e muito controvertidos quando se trata da observação da verdadeira natureza da mulher ${ }^{8}$. Woolf desconstrói a forma como é proferida uma conferência e a apresentação de uma dissertação científica, e também a crença numa verdade absoluta e universal a respeito do sexo feminino.

Justamente, a dita desconstrução 9 atua sobre esses conceitos "universais", através, por exemplo, do esforço para fazer com que sua platéia e seus leitores entendam que tudo o que foi dito e que o que está sendo dito é, na realidade, uma verdade provisória e localizada, inscrita como opinião. Tal conhecimento (ou crença) não inclui garantia alguma da própria validade do que quer que seja e expõe os paradoxos das convicções e dos paradigmas dos ouvintes e leitores, construídos a partir de discursos masculinos com os quais pretende polemizar.

Percebe-se também que Virginia Woolf constrói sua reflexão tendo como contexto a abrangência intelectual e o predomínio das potências européias, no início do século XX, a urbanização das metrópoles e a indagação sobre as condições e a situação da mulher nessa nova perspectiva de mundo e de sociedade (BONNICI, op. cit., p. 198). Aqui, então, as verdades provisórias e localizadas servem também para reflexão sobre a condição e situação da mulher em países do continente africano e de outros lugares que foram em algum momento colônias de países europeus, como o conceito do mito do grupo monolítico (ibid., p. 202), segundo o qual todas as mulheres possuem os mesmos problemas sendo elas pós-coloniais ${ }^{10}$ ou nascidas e criadas nas ex-metrópoles. Esse conceito foi criado pelo feminismo ocidental, que na verdade detinha o status quo de colonizador. Não existe, portanto, um conceito homogêneo de inferiorização e marginalização da mulher nem de seu papel determinado em uma sociedade. A mulher, a partir do seu corpo vivido, vai construir e mostrar seus obstáculos através de suas ações, e o significado destas nas interações sociais concretiza-se em fenômenos como a luta pelo sufrágio e o direito da mulher à educação.

No estudo de Virginia Woolf, a natureza dogmática da mulher entra em controvérsia com as convenções, como o casamento, e a mulher passa a refletir sobre a liberdade de pensamento e a respeito de sua condição. Virginia Woolf traz as mulheres espectadoras e leitoras para o centro da discussão com a construção de uma "verdade" mais compatível com sua realidade, incumbindo-a de concluir ela mesma o sentido das reflexões apresentadas. A validade do discurso proferido por Woolf permite que o mesmo possa se situar no campo de leitura de cada um que o lê e o entende. A verdade a priori, aqui, possui o caráter de descentramento do sujeito autoral, o que permite que seja discutido por qualquer mulher em qualquer contexto desde que lhe seja possibilitado o entendimento, criando uma dialética atemporal que serve de panteão não só para a autora, mas para qualquer movimento feminista e suas subjetividades distintas.

A postura adotada por Virginia Woolf se amplia em Um teto todo seu, encarando suas leitoras e ouvintes como escritoras em potencial e as fazendo perceber sua tese, dita de maneira bem clara: a mulher precisa ter dinheiro e um teto todo seu se pretende mesmo escrever ficção ${ }^{11}$. Então, o que se passa a discutir não é mais qual a verdadeira natureza da mulher, mas sim, qual sua condição na sociedade, sua condição feminina, que na maioria das vezes é somente encarada como procriadora dos descendentes do homem, entendido por muitos como seu modo e sua condição de vida no universo 
estático da natureza, que concebido metafisicamente, cede lugar à dinâmica das relações sociais.

Quando Virginia Woolf assinala a necessidade de que a mulher tenha um "quarto próprio" (um teto) e uma quantia em dinheiro anualmente, que lhe possibilite autonomia, faz a denúncia da pobreza exacerbante das mulheres. Isso não acontece somente em sua época, mas no que podemos perceber na atualidade, no seu quase que impossibilitado e escasso acesso à educação e ao mercado de trabalho, por não estar capacitada e por ser subordinada ao homem e a toda a hierarquização construída patriarcalmente. Virginia Woolf utiliza-se do exemplo da mulher inglesa que até o final do século XIX era "aliviada" de posse de bens materiais, restrita à casa, aos afazeres domésticos e à procriação, não participante dos negócios e das discussões que se referiam à esfera pública. Tal conceito de feminismo foi criado pelo patriarcalismo machista que domina nossa cultura ainda hoje.

Virginia Woolf, em toda essa sua reflexão, articula implicitamente a perspectiva de gênero com a de classe social a partir do postulado marxista da determinação em última instância do fator econômico que a influencia, ou melhor, a condiciona à pobreza, tornado-a submissa, explorando-a e a excluindo culturalmente. Virginia utilizase dos exemplos de investimentos feitos no passado, como as fellowships ${ }^{12}$, que no presente garantem a construção de uma cultura, no caso a das Universidades e de seus fundamentos científicos pesquisados e corroborados que auxiliam a história e as ciências.

Virginia Woolf enfatiza a estreita relação criada pelo capitalismo entre renda e liberdade individual, pois a pobreza pode criar danos irreversíveis à intelectualidade, impossibilitando quem quer que seja de criar, de escrever, de se expressar, ou, como ela mesma diz: "não se pode pensar bem, amar bem, dormir bem, quando não se jantou bem" (WOOLF, op. cit., p. 23). Prosseguindo em suas afirmações, Virginia Woolf apresenta-nos o pensamento do professor Trevelyan ${ }^{13}$, o qual a faz concluir que um gênio como Shakespeare no século XVI não "existiria" entre pessoas trabalhadoras, que não possuíam instrução e que fossem humildes financeiramente. Hoje, ainda, é difícil encontrar essa genialidade em alguém que tenha nascido nas classes operárias, que não tenha tido desde a infância possibilidades que o levassem à instrução e ao conhecimento sem que precisasse se preocupar em adquirir primeiro uma renda e um lugar para que pudesse desenvolver seu pensamento. Segundo o próprio professor Trevelyan, muito menos as mulheres tinham tal privilégio de virem a se tornar intelectuais e a escreverem grandes obras da literatura, pois antes mesmo de largarem as brincadeiras com bonecas, eram forçadas por seus pais ao trabalho doméstico e ao casamento, presas pelo poder da lei e dos costumes. Mas é claro que nem por isso elas deixaram de ser talentosas e ainda o são até hoje dentro das classes operárias e de tantas outras. O que acontece, é que poucas afloram tais talentos e são impossibilitadas de algum dia vir a demonstrá-los. (WOOLF, 2004, p. 53)

$\mathrm{Na}$ equiparação que Virginia Woolf faz entre o trabalho doméstico e o trabalho operário, ela afirma analogamente a citação de outrem ${ }^{14}$ de que nenhuma mulher jamais poderia alcançar o gênio de Shakespeare, apropriando-se de tal afirmação justamente para inverter o sentido misógino nela vigente. Passa a ser pressuposto básico, então, para a atividade literária, que renda e propriedade não são dádivas da natureza, mas são determinantes primordiais que propiciam a instrução e a aquisição de um quarto próprio. A essência natural do papel da mulher na sociedade à esfera doméstica tem seus fundamentos questionados; o talento criador não é exclusivo dos homens, que dominam e governam a escala social, mas os meios que detêm e que se utilizam para desenvolver a atividade literária, sim, dado que possuem renda e propriedade para 
criarem. O imperativo de se ter um teto todo seu não está apenas vinculado ao aprimoramento de um talento artístico, mas vai além, sendo fundamental para a afirmação da mulher como sujeito de sua história, que a percebe e a constrói.

Virginia Woolf desdobra várias vezes a tese do "teto todo seu". Ela responsabiliza a pobreza a que todas as mulheres inglesas estiveram submetidas pela debilidade da tradição literária feminina em seu país. Talvez realmente tenha faltado um sujeito feminino que tivesse se voltado para a escrita de sua história, não deixando seus relatos para que os homens o fizessem. Virginia Woolf (2004, p. 52) então afirma, peremptoriamente, que "a mulher jamais escreve sua própria vida e raramente mantém um diário - existe apenas um punhado de cartas. Não deixou peças ou poemas pelos quais possamos julgá-la”. Com tal afirmação, a autora demonstra perceber a parcialidade e a insuficiência da historiografia existente no tocante à literatura feminina e constata que a universidade e as instituições educacionais nada mais eram do que espaços patriarcais, exortando então todas as mulheres daquele momento, bem como as que hoje procuram construir uma literatura pós-colonial feminista, a reescreverem tal história, de modo que se incluam efetivamente e assumam o papel de protagonistas. Como diz em sua obra, por que não elas, as mulheres, poderiam acrescentar à história um novo suplemento, figurando sem impropriedade? Sempre que as vemos na história da literatura são aparições de relance na vida de grandes homens e logo são colocadas de lado, sem que se dê a devida importância ou valor a suas próprias vidas, suas histórias e seu pensamento. (id.)

A "não-propriedade"15 da mulher que Virginia Woolf discute também se aplica à causa pós-colonial dos países africanos, por exemplo, pois os pan-africanistas buscam atualmente mostrar a diversidade cultural que existe em seu continente geográfico, apontando para o fato de que o vazio cultural só existiu do ponto de vista do cânone europeu patriarcal. Existe lá, de fato, uma diversidade cultural, que possui tradições e relatos históricos diversos, de muito valor no tocante à apropriação autóctone dos “espaços” geográficos e culturais (APPIAH, 1997, p. 47).

Ao invés da do suplemento, quem sabe caiba melhor aqui a lógica do complemento, ou seja, o movimento que supre uma falta ou completa o que se mantém incompleto, no caso, a história da Inglaterra, terra de Virginia Woolf, a historiografia da literatura ou, para o pós-colonialismo, as histórias contadas pelos personagens que antes só figuravam como meros colonizados na forma canônica européia. Até aqui, Woolf estaria, portanto, dentro de uma estrutura metafísica de pensamento. Mas o argumento não se sustenta diante do perfil eminentemente masculino e excludente da história oficial. O que Virginia Woolf encontrou em suas pesquisas nas universidades inglesas e nos museus foram prateleiras repletas de obras que narram os feitos de grandes nomes masculinos, mostrando efetivamente que a historiografia da literatura não foi feita por mulheres e nem lhes foi dada a oportunidade de participar dessa construção. Criando a fictícia Judith ${ }^{16}$, suposta irmã de Shakespeare, Woolf conclui que mesmo que Judith tivesse existido e igualmente ao irmão tivesse sido uma grande literata, em algum momento, por conta das circunstâncias que condicionavam a mulher, ela se deixaria induzir culturalmente pela sua inferiorização pelo homem e jamais tomaria parte da história da literatura efetivamente ou teria reconhecido seu devido valor, afastando-se da oportunidade de criar e de fazer parte da literatura de seu povo ${ }^{17}$.

A partir da doxa ${ }^{18}$ patriarcal vigente, Woolf desconstrói os indivíduos e os vê não como entidades rígidas e intactas, mas como seres que se formam a partir do apogeu das cidades, da urbanização dos grandes centros. Londres é descrita como uma grande oficina, ou uma grande máquina onde são moldadas as pessoas. Assim, o Museu Britânico, que serve de lugar de pesquisa para sua empreitada de encontrar as mulheres 
na historiografia da literatura, é visto como um departamento dessa grande oficina (WOOLF, 2004, p. 32). Este lugar, segundo ela própria explicita, contém e constrói a narrativa das ações femininas na história das artes, das letras e de toda a vida na Inglaterra. Nessa interpretação da cidade e do museu como "fábricas e trabalhadores", conseqüentemente, dos desejos e comportamentos, Virginia Woolf vem antecipar os conceitos que irão fundar o Pós-Estruturalismo, e acaba servindo de base para os movimentos feministas da década de 80 do século XX, por conta de seu olhar para o mecanicismo da indústria e das lutas das organizações sindicais.

O que resta então é a comparação das contribuições de homens e mulheres à historiografia literária a partir das condições materiais que estes tiveram para criar e expressar suas idéias, tomando como base construções metafísicas a respeito de ambos os sexos. A mulher figura no universo patriarcal como "espelho do homem"19, conformista com sua identidade periférica e com sua exclusão da renda e da propriedade. Como diz Virginia Woolf, ela reflete o homem com o dobro de seu tamanho, fazendo com que ele possa ver-se potencializado e maximizado em suas ações e grandeza; sem tal vislumbramento, tudo o que existisse perderia a graça. Assim, Woolf conclui por que grandes nomes do poder, como Napoleão e Mussolini ${ }^{20}$, insistiam na inferioridade da mulher: segundo ela, se as mulheres não parecessem inferiores aos olhos desses homens, eles perderiam grandeza (WOOLF, 2004, p. 42).

Essa metáfora do espelho remete à passividade destinada pela história à esposa. De acordo com as concepções de Benjamin Constant (1985, p. 16), por exemplo, a mulher deve aguardar sempre afetuosa a chegada do pai, do provedor da família, e cobri-lo de ternura e carinhos após o cansativo labor diário. Aqui podemos perceber e fazer mais um paralelo entre Feminismo e Pós-Colonialismo, como descrito por Teolinda Gersão em sua obra de ficção $A$ árvore das palavras (2004), narrativa construída a partir da vivência da autora portuguesa em Moçambique à época da guerra de independência do país na década de 60 do século XX. No mesmo momento em que começa a conscientização para que aquele território se torne um país livre de seu colonizador, as mulheres de lá começam a enfrentar outro confronto conceitual: o da subjetividade feminina moçambicana e negra. A emancipação dessas mulheres não enfrenta os mesmos obstáculos que a da mulher branca européia ou norte-americana, da mesma forma o país que está se formando não se enquadra nos conceitos de nação criados pela Europa a partir da formação dos Estados nacionais no século XV ou dos ideais republicanos e liberais da Revolução Francesa. Moçambique no caso, como outros países que se libertaram na África na segunda metade do século XX, possui uma multiculturalidade que não condiz com a conceitualização européia de que uma raça possui uma única cultura ${ }^{21}$. Assim como o país que está se formando não é igual conceitualmente aos outros países estruturados a partir do pensamento europeu, a luta das mulheres negras africanas pela independência do homem e do país também se diferencia. Elas são dominadas por uma cultura que as oprime e as subjuga como meramente existentes em função do homem e de procriar e trabalhar para ele. Procuram sobreviver de qualquer maneira e, com tal ação, mesmo sem saberem da importância, são as verdadeiras construtoras e articuladoras da cultura, mantendo seu povo em contanto com suas histórias e suas interpretações da vida e dos costumes de forma oral (GERSÃO, 2004, p. 162), fugindo assim, do modelo canônico literário europeu.

A atividade masculina, padronizada categoricamente pela cultura patriarcal, caracteriza-se então pelos afazeres externos, ao passo que a atividade feminina, que também tem seu conceito construído pelo homem, se reduz apenas aos afazeres domésticos. Quanto maior for o caráter doméstico da atividade feminina, maior e mais produtiva será a atividade do homem. Mas a mulher entendida como espelho que reflete 
o homem remete-nos a algo ainda mais profundo, ao caráter relacional que vem a ser construído a partir das identidades de gênero, ganhando contornos filosóficos como o de pensar o ser como relacionar-se, projetar-se no outro. Assim, a reflexão exposta por Virginia Woolf não se afasta da posição política, pois, se a identidade inexiste sem a alteridade, é preciso quebrar o absoluto que dá para uns (os homens) o topo da civilização e para outros (as mulheres) condições submissas e inferiores numa hierarquia criada e não-natural.

Virginia Woolf leu e serviu de interlocutora da psicanálise freudiana, destacando a força e o imaginário do comportamento social e conjugal. Quando caracteriza o sexo masculino e o sexo feminino como sendo gênero de "criaturas de ilusão" (2004, p. 41), demonstra sua compreensão do ser humano como sujeito desejante, movido por paixões, pulsões e fantasias. Referindo-se à luta constante em que homens e mulheres se engalfinham, denuncia a idéia da inferioridade inata como estratégia patriarcal.

Em alguns momentos, percebe-se na leitura de Um teto todo seu que Virginia Woolf cede à tentação de simplesmente reverter a hierarquia de poder do gênero, mas, logo seu discurso caminha para a desconstrução do binarismo que envolve os gêneros masculino e feminino em pólos opostos regidos pelas relações de poder. Aqui, valemonos da interpretação da idéia de androginia da mente apresentada pela autora e tomada de empréstimo a Coleridge ${ }^{22}$ (WOOLF, 2004, p. 108), que serve de suporte não somente à teoria da cooperação e da complementaridade entre homem e mulher, mas para, sobretudo, aproximar e destacar a convivência entre os extremos dos dois gêneros, garantindo maior felicidade para suas vidas e uma intelectualidade mais fértil. Uma mente andrógina, na qual um gênero não se sobrepusesse ao outro, facilitaria a convivência e propiciaria maior abrangência cognitiva. A partir dessa fusão, a mente humana não criaria mais empecilhos, transmitindo as emoções de maneira fluida, integralizando todas suas capacidades cognitivas.

Operacionalizando seu pensamento desta forma, Virginia Woolf desconstrói a historiografia literária, antecipando um movimento que intelectuais como Derrida fariam com mais afinco na segunda metade do século XX. A metáfora da androginia da mente possibilita entender a atração que ocorreria se, interpenetrando-se, a parte masculina e a feminina da mente assumissem cada uma a parte que antes era destinada à outra. Dissolver-se-ia a barreira que antagoniza homens e mulheres. Virginia Woolf afirma também que o pessoal é político, que a individualidade não deixa de ser social, apropriando-se de valores caros ao pensamento ocidental, como a liberdade e a paz, a fim de situá-los no âmbito das relações de gênero. Quando incita homens e mulheres à colaboração mútua e à tolerância, está de fato conclamando todos os intelectuais e as mulheres ao fim da dominação do gênero masculino e pedindo o fim do patriarcado, visando a modificar a sociedade e dar possibilidades iguais a todos.

A androginia textual, harmonizadora da fíç̧ão e do ensaio, mostra na textualidade de Virginia Woolf todo um pensamento, o da androginia da mente, que, abala os sentidos da verdade patriarcal. Ao desconstruir os alicerces da doxa masculina, a androginia proposta por Woolf antecipa em mais de meio século a desconstrução dos binarismos hierárquicos históricos, concedendo, então, fundamentos filosóficos aos estudos pós-modernos e pós-coloniais, tendo em vista a consciência da situação da mulher no mundo de hoje.

\section{Considerações e relações sobre o feminismo de Virginia Woolf e o pós-colonialismo}

Da mesma maneira que Virginia Woolf encontrou em sua pesquisa e relatou em seu ensaio a ausência da participação das mulheres na historiografia da literatura 
européia, percebemos hoje na construção e na definição da teoria pós-colonial que os países que foram um dia colônia de metrópoles européias também foram excluídos por não fazerem parte do cânone patriarcal eurocêntrico estabelecido. Assim, a semelhança entre o movimento feminista e o pós-colonialista, na busca por preencher um suposto vazio cultural, nada mais é do que estabelecer e resgatar seus valores culturais e fazer com que sejam vistos por outras formações culturais e, principalmente, destacar a forma como são expressas e registradas em cada contexto, seja na oralidade, na dança, na escrita ou em outras manifestações culturais vigentes.

Utilizando a desconstrução desenvolvida por Derrida e analisando a história da hegemonia do homem sob a mulher e a hegemonia do poder que os valores europeus exerceram e exercem (hoje juntamente com os norte-americanos), percebemos realmente que toda a origem de dominação está estruturada no pensamento patriarcal e na inferiorização do outro para que o homem, subseqüentemente os detentores dos poderes de comunicação e políticos, continue dominando, criando sempre uma "periferia" que "não fará parte da história".

Frantz Fanon, em Pele negra, máscaras brancas (1975), aponta também para essa relação do feminismo que discutimos e observamos em Um teto todo seu de Virginia Woolf com o pós-colonialismo e a inferiorização múltipla da mulher negra que era colonizada pelo homem branco europeu. O homem, segundo Fanon, é o centro de onde partiram as idéias e formularam-se teorias para garantir sua superioridade em relação ao seu semelhante. Nesse movimento de articulações de dominação, percebe-se a agressividade, o engendramento de sujeição e da conquista do outro. A partir dessa teorização de poder do homem metropolitano sobre a mulher ou sobre o colonizado, ele próprio nomeou seus atos como éticos, universais e justificados para a estabilização do que considerava ele ser o bem (ibid., p. 55). Fanon ainda diz que o que o homem europeu desejou para os outros, a partir do que queria para si, integrar os valores permanentes para a realidade humana, requerendo a mobilização das chamadas instâncias psíquicas para que o outro inferiorizado não fosse contra o bem garantido pelo homem que domina. Nesta relação de colonizado e colonizador, o homem dominou e domina (ou procura dominar), em muitas culturas, até hoje, a mulher e o diferente. $\mathrm{O}$ pensamento europeu e os homens desse continente conquistaram regiões inóspitas, estabilizando as ações daqueles que nelas viviam através do pensamento patriarcal desenvolvido e consolidado historicamente.

A transformação social que decorre do feminismo proposto por Virginia Woolf em Um teto todo seu e de tantos outros estudos e idéias feministas que surgiram posteriormente nos levam a entender e a fazer com haja realmente uma transformação e não somente a aceitação do cânone estabelecido. Como mostra Fanon (1975, p. 56) em um exemplo de seu livro, as mulheres negras que se casavam com homens brancos na época da colonização não adquiriam o mesmo status e a mesma respeitabilidade que a mulher branca tinha por parte do homem branco. Assim, novas idéias e teorias devem ser formadas e outras reformuladas para que tanto ex-colonizados como as mulheres subjugadas possam fazer parte efetivamente da historiografia literária que se constrói.

\footnotetext{
${ }^{1}$ Nessa perspectiva, a violência não se resume a atos de agressão física, mas decorre igualmente de uma normalização, na cultura, da discriminação e da submissão feminina. Aliás, o avanço do processo de civilização, entre os séculos XVI e XVIII, corresponderia a um recuo da violência bruta, substituindo-se os enfrentamentos corporais por lutas simbólicas. Nesse período, a construção da identidade feminina se pautaria na interiorização pelas mulheres das normas enunciadas pelos discursos masculinos; fato correspondente a uma violência simbólica que supõe a adesão dos dominados às categorias que embasam
} 
sua dominação. Um objeto maior da história das mulheres, neste momento, consiste no estudo dos discursos e das práticas, manifestos em registros múltiplos, que buscariam garantir o consentimento feminino às representações dominantes da diferença entre os sexos: a divisão das atribuições e dos espaços, a inferioridade jurídica, a inculcação escolar dos papéis sociais, a exclusão da esfera pública, etc. Assim, definir a submissão imposta às mulheres como uma violência simbólica ajuda a compreender como a relação de dominação - que é uma relação histórica, cultural e lingüisticamente construída - é sempre afirmada como uma diferença de ordem natural, radical, irredutível, universal (CHARTIER, 1995, p. 40-44).

${ }^{2} \Sigma \alpha \pi \varphi \omega ́$ (Sappho - grego antigo - 520 a. C.) Sappho, de Lesbos. Foi uma das maiores poetas da antigüidade, mas seus poemas estão quase todos perdidos ou destruídos. Foi a maior inspiradora de poetas destes 15 séculos passados, o que lhe valeu o título de décima musa. De seu nome e de sua terra natal derivaram os epítetos "safada" e "lésbica" para denominar as que antes eram chamadas de tribadistas. Apesar de haverem pouquíssimas informações objetivas a seu respeito, pode-se dizer com certeza que Sappho vivia em Lesbos, era de família aristocrata, foi exilada da ilha durante um período por desavenças políticas, cantava poemas que ficaram famosíssimos. (ABBAGNANO, 2000)

3 ...como fazendo parte de um sistema socialmente imposto pela ordem patriarcal ou androcêntrico. A vontade de intervir coletivamente para mudar esse sistema-idéia de auto-afirmação; a fé na possibilidade de uma tal mudança; a referência utópica (no sentido grego do termo: o que não existe) a uma ordem social livre de dominação sexual, a partir da qual se julga a realidade existente. (VARIKAS, 1979)

${ }^{4}$ Um teto todo seu baseia-se em dois artigos lidos perante a Sociedade das Artes, em Newnham, e a Odtaa, em Girton, em outubro de 1928. Os artigos eram demasiadamente extensos para serem lidos na íntegra e foram posteriormente alterados e ampliados.

${ }^{5}$ Mesmo que o estudo de gênero seja amplo e não exclusivo do advento feminista e de seus estudos, mas de toda e qualquer performance que parta deste conceito. (BUTLER, 2003, p 15)

6 "Mas, para compensar um pouco, vou fazer o possível para mostrar-lhes como cheguei a este conceito do teto e do dinheiro. Vou expor diante de todos, tão livre e integralmente quanto puder, o encadeamento de idéias que me levou a pensar nisso. Talvez, se eu revelar as idéias e preconceitos que estão por trás dessa afirmação, vocês descubram que eles têm alguma relação com as mulheres e outra com a ficção. De qualquer modo, quando um tema é altamente controvertido - e assim é qualquer questão sobre o sexo -, não se pode pretender dizer a verdade. Pode-se apenas mostrar como se chegou a qualquer opinião que de fato se tenha." (WOOLF, 2004, p. 8)

7 "“[...] a união do homem e da mulher resulta na satisfação maior, na mais completa felicidade. [...] levame a pensar e também a perguntar se haverá dois sexos na mente, correspondendo aos dois sexos do corpo, e se eles precisariam ser unidos para se conseguir completa satisfação e felicidade. [...] em cada um de nós preside os dois sexos, um masculino e um feminino; e no cérebro do homem, o homem predomina sobre a mulher, e, no cérebro da mulher, a mulher predomina sobre o homem. $\mathrm{O}$ estado normal e confortável é aquele em que os dois convivem em harmonia. [...] Coleridge talvez tenha querido referirse a isso quando disse que as grandes mentes são andróginas." (WOOLF, 2004, p. 108)

8 "Esquivei-me ao dever de chegar a uma conclusão sobre essas duas questões - a mulher e a ficção, para mim, permanecem como problemas não solucionados.” (WOOLF, 2004, p 8)

9 Analisando a obra de Virginia Woolf, percebemos que ela utilizou muito em seus ensaios a desconstrução de texto na análise que fazia da historiografia da literatura e dos textos literários, mesmo que o termo "desconstrução" esteja tradicionalmente vinculado ao trabalho de Jacques Derrida e ao PósEstruturalismo, na segunda metade do século XX. "Desconstrução" é o nome dado à operação crítica através da qual se analisa uma obra através dos supostos primeiros princípios que a estruturam, negado-os e mostrando que seus significados comumente podem levar a outras interpretações do texto. (EAGLETON, 2001, p. 182)

${ }^{10}$ Nascidas ou vivendo em países que foram colônias de países europeus.

${ }^{11}$ WOOLF, Virginia. 2004. p 8

${ }^{12}$ As fellowships eram sociedades de estudantes graduados de uma certa universidade, os fellows, como eram chamados, e eram mantidas através de um fundo especial a fim de realizar determinados cursos de pós-graduação. (WOOLF, 2004, p. 10)

${ }^{13}$ George Macaulay Trevelyan (16 de fevereiro de 1876 - 21 de Julho de 1962), autor de English Social History: A Survey of Six Centuries from Chaucer to Queen Victoria (1942).

14 “... o bispo tinha razão pelo menos nisso: teria sido impossível, completa e inteiramente, a qualquer mulher ter escrito as peças de Shakespeare na época de Shakespeare.” (WOOLF, 2004, p 53)

${ }^{15}$ Leia-se: o fato de não terem posses, propriedades ou quaisquer outros bens.

16 "Permita-me imaginar, já que é tão difícil descobrir fatos, o que teria acontecido se Shakespeare tivesse tido uma irmã maravilhosamente dotada, chamada, digamos, Judith.” (WOOLF, 2004, p 53) 
${ }^{17}$ Desde o século XV, trupes teatrais agregavam-se aos domínios de senhores nobres e reis, constituindo o chamado teatro elizabetano. Os atores - ainda com a participação exclusiva de homens - eram empregados pela nobreza e por membros da realeza, assim como William Shakespeare.

${ }^{18}$ Husserl indica com o qualificativo "opinião" (de dóxico - em alemão doxisch) todos os caracteres próprios da crença. (Cf. ABBAGNANO, 2000, p. 294)

19 "Em todos esses séculos, as mulheres têm servido de espelhos dotados do mágico e delicioso poder de refletir a figura do homem com o dobro do seu tamanho natural. Sem esse poder, a Terra provavelmente ainda seria pântano e selva." (WOOLF, 2004, p. 42)

${ }^{20}$ Napoleão achava as mulheres incapazes de se instruírem e Mussolini as desprezava. (WOOLF, 2004, p. 36-37)

${ }^{21} \mathrm{O}$ pensamento ocidental durante muito tempo se orientou para a crença no fato de que a raça está ligada a critérios biológicos que determinam a diferenciação de indivíduos através de caracteres hereditários, inclusive culturais e morais, de modo que se pensava que todos de uma mesma raça fazem parte de uma mesma cultura. (PINTO, 2004)

${ }^{22}$ Samuel Taylor Coleridge (1772-1834), autor de Lyrical ballads, ligado ao grupo dos lake poets.

\section{REFERÊNCIAS}

ABBAGNANO, Nicola. Dicionário de Filosofia. São Paulo: Martins Fontes, 2000.

APPIAH, Kwame Anthony. Na casa de meu pai: A África na filosofia cultural. Trad. Vera Ribeiro. Rio de Janeiro: Contraponto, 1997.

BONNICI, Thomas. Tendências do Feminismo no contexto pós-colonial. In: PORTO, Maria Bernadete; REIS, Lívia de Freitas; VIANNA, Lucia Helena. Mulher e Literatura. Niterói: EdUFF, 1999.

BUTLER, Judith. Problemas de gênero: Feminismo e subversão da identidade. Rio de Janeiro: Civilização Brasileira, 2003.

CHARTIER, Roger. Diferenças entre os sexos e dominação simbólica (nota crítica). Cadernos Pagu - Fazendo história das mulheres. n. 4. Campinas: Núcleo de Estudos de Gênero, 1995.

CONSTANT, Benjamin. Da liberdade dos antigos comparada à dos modernos. In: MORAES, João Quartim de (ed.). Filosofia politica. V. 2. Porto Alegre; Campinas: L\&PM; UFRGS; Unicamp, 1985.

EAGLETON, Terry. Teoria da literatura: uma introdução. São Paulo: Martins Fontes, 2001.

FANON, Frantz. Pele negra, máscaras brancas. Trad. Alexandre Pomar. Porto: Paisagem, 1975.

GERSÃO, Teolinda. A árvore das palavras. São Paulo: Planeta, 2004.

MOTTA, Ivania Pocinho. A importância de ser Mary: uma defesa dos direitos da mulher por Mary Wollstonecraft. Dissertação de Mestrado em História. São Paulo: USP, 2003. 
PINTO, Alberto Oliveira. O discurso da 'raça' em Angola: um obstáculo à construção da democracia? Liberdade. Revista de Cultura e Contracultura. Anais Científicos da Universidade Independente, Nova Série. N. 7, Lisboa: Estúdios Cor, 2004.

Ed. Faculdade de Letras da Universidade de Lisboa, 2006.

VARIKAS, Eleni. Jornal das damas: feminismo no século XX na Grécia. Revista de Sociologia. São Paulo: Núcleo de Estudos da Mulher e Relações Sociais de Gênero (USP), 1979.

WOOLF, Virginia. Um teto todo seu. Trad. Vera Ribeiro. 2. ed. Rio de Janeiro: Nova Fronteira, 2004. 